\title{
Synergy of Top Management Team Demographics, Strategy and Structure: Empirical Evidence on Performance of Public Enterprises
}

\author{
Zachary B. Awino ${ }^{1} \&$ Bwire Joseph Francis ${ }^{2}$ \\ ${ }^{1}$ Associate Professor of Strategy and Supply Chain Management, School of Business, University of Nairobi, \\ Kenya \\ ${ }^{2} \mathrm{PhD}$ Candidate, School of Business, University of Nairobi, Kenya \\ Correspondence: Zachary B. Awino, School of Business, University of Nairobi, P.O. Box 30197 - 00100 Nairobi, \\ Kenya.E-mail: zb.awino@uonbi.ac.ke
}

Received: December 3, 2017

doi:10.5539/ijbm.v13n2p108
Accepted: January 7, $2018 \quad$ Online Published: January 15, 2018

URL: https://doi.org/10.5539/ijbm.v13n2p108

\begin{abstract}
The study conceptualized the collective effect of TMT demographics, corporate strategy and organizational structure on performance of Kenyan PEs. TMT demographics have been posited to influence performance however; this position has been largely tautological and hence required more empirical testing. The study adopted a cross-sectional descriptive survey in which a semi-structured questionnaire was used to obtain data. The questionnaire was administered through a drop and pick method to a sample of 117 Chief Executive Officers. The study used both descriptive and inferential statistics for purposes of data analysis. Descriptive statistics used included mean, standard deviation, coefficients of variation (CVs) and t-tests. Inferential analysis involved the use of multivariate and hierarchical regression analyses. The findings of the study indicated that jointly TMT demographics, corporate strategy and organizational structure significantly influenced performance of PEs. The findings informed theories (upper echelon, configuration, institutional an behavioural theory of the firm) by showing their relevance and applicability in day-to-day organizational operation; decision makers at managerial level are guided on how to choose TMTs with the right mix of demographics, and policy makers on development of guidelines and policies that define the required TMT demographics during recruitment who can develop corporate strategies and adopt structures that bring about stellar performance. The limitations of this study pin-points some areas that need further research in the future. For instance, a qualitative research with variables such as culture and leadership could be considered for future research.
\end{abstract}

Keywords: Kenya, Performance, Public Enterprises (PEs), Strategy, Structure, Synergy, Top Management Team Demographics

\section{Introduction}

Organizations are continuously keen on their performance. Strategic management practitioners and researchers are continuously seeking to establish which factors have the highest impact on organizational performance. Awino (2013) posited that no single factor can fully explain performance and thus need to combine various factors. This could largely be because performance is multifaceted and multidimensional (Nyangau, 2015; Venkatraman \& Ramanujam, 1986). Since the swing of the pendulum occasioned by the propositions of Hambrick and Mason (1984) in the upper echelons theory, researchers have attempted to study the influence of various dimensions of Top Management Team (TMT) on organizational performance. TMTs are those executives holding senior offices and have influence on organizational strategic outcomes (Kasomi, 2015; Mkalama, 2014). The influence of TMT demographics on organizational performance could be subject to other factors. For instance, TMTs demographics influence organizational performance by the strategic decisions that they make (Nielsen, 2010). The organizational structure could equally moderate the relationship between TMTs demographics and organizational performance.

The key variables are TMT demographics, corporate strategy, organizational structure and performance. According to Andrews (1980) corporate strategy must dominate the design of organizational structure and processes. Thus until we know the corporate strategy we cannot begin to specify the appropriate organizational structure. Sababu (2007) agreed with this view stating that a change in the corporate strategy often required changes in the way an organization was structured. Organizational structure dictates how objectives and policies 
are established and how they are achieved. Wolf and Engelhoff (2002) advocated for a fit between corporate strategy and organizational structure, rather than the quasi-linear emphasis. This leads to reciprocal relationships in reverse causality between strategy and structure thus influencing organizational performance.

The hard questions at any TMT's countenance organizations are deciding what structures are suitable for the chosen strategy to pursue. This may require the construction of structure configurations with other factors in mind to enhance synergy. The effects of TMT demographics on performance range from positive through non-significant to negative (Nielsen \& Nielsen, 2013). Organizational performance gives a broad picture of the TMT and actions of managers whose role in the organization is pivotal (Nielsen, 2013). TMT demographics are believed to influence the decisions that they make in terms of corporate strategy and organizational structure adopted that in turn will produce outcomes, notably organizational performance (Bagire, 2012).

\section{Materials and Literature Review}

The study was anchored in four theories namely upper echelons theory (Hambrick \& Mason, 1984), configuration theory (Miller \& Friesen, 1984), institutional theory and behavioural theory of the firm. The upper echelons theory laid the foundation upon which the interface of TMT demographics and organizational performance is anchored. Some key postulations of upper echelons theory is that strategic decisions adopted by organizations and the performance levels of organizations are partially predicted by management demographic characteristics which include functional area, gender, educational level, age and tenure in the organization (Hambrick and Mason, 1984). TMTs in organizations are quite critical since they are the ones who develop strategies which align their organizations to the environment thus remaining competitive. The strategic positions adopted by organizations are usually determined by strategic propositions made by their TMTs based on the way the TMTs perceive and interpret the happenings in the environment (Pearce, Robinson \& Mital, 2012).

Configuration theory argues that interaction between strategy, structure, and the surrounding generates archetypes or dispositions. Consequently, these kinds of archetypes provide a rich description of the organizations, thus disclosing their complicated, gestalt and systematic complexion. The theory holds that while a firm may copy another's strategy, it can never copy the way strategy elements; TMT demographics and organizational structure are configured into a synergetic whole to produce stellar performance (Miller \& Friesen, 1984). According to Hunter (2015), organizations are organized into formal structure whereby they exhibit a hierarchical pattern of authority relationships that varies along key measurable structural dimensions including: specialization, span of control, vertical and horizontal differentiation, centralization, and formalization. This implies that organizations maintain prescribed reporting relationships and their correlates.

The organizational structure of a firm is explained by the institutional theory (Kondra \& Hinings, 1998). Institutional theory has its centre of attention directed at the deeper and more resilient aspects of organizational structures (Chandler, 1962; Zucker, 1987). For this reason, institutional theory provides authoritative guidelines for a firm to coordinate teams (Scott, 2004). The institutional theory framework is designed to explain how the various elements are generated, diffused and adopted over a period of time; and how they diminish and fall in a state of not being used. Burns and Stalker (1961) noted that there are two types of organizational structures, bureaucratic and organic while studying Scottish electronic firms. The two types of structures were adopted as they manifest in the context of this study.

Cyert and March (1963) and Simon (1959) observed that the behavioural theory not only inaugurate sociological facets to the economic theory, but also spotlights the responsibility of individuals. Behavioural theory thus perceives firms as being comprised of a group of independent members with individual goals and desires. The behavioural theory underlines the fact that institutional objectives are not stipulated at the institution but at the personal level and are divergent in nature. The behavioural theory of the firm maintains that decision makers set targets or aspiration levels of desirable performance and that whenever their targets are not met, they respond by seeking for new ideas and becoming more willing to accept risky solutions (Desai, 2016). The theory therefore centres on the discretion of TMT in corporate strategy generation and implementation based on what type of structure they adopt. Corporate strategy therefore involved decisions on the mix and emphases of business portfolio of Kenyan PEs which had to do with cost leadership, outsourcing, differentiation and diversification.

Finkelstein, Hambrick and Cannella (2009) observed that globally out of every ten PEs eight have a diverse TMT that influences which corporate strategy to adopt. They also note that TMT is highly influenced by the organizational structure in place because an organizational structure commands the flow of information among the TMT. Finkelstein et al. (2009) further stated that in the traditional organizational structure where the hierarchy was emphasized TMT relation was poor and this would lead to frequent state intervention that impacted negatively in the performance of PEs. Currently with the emphasis of corporate governance and role of 
entrepreneurship has resulted to collaborative TMT this has yielded flexible organizational structures that are inclusive which improves on performance.

Munyoki (2015) notes that in Africa the traditional community did not exhibit any PEs, however immediately after independence countries in Sub-Saharan Africa (SSA) established PEs. The performance of these entities has been poor for the past 50 years due to TMT. Munyoki (2015) further observes that for every ten PEs in SSA only one is functional and the major case of the poor performance is incompetence of TMT to select the best corporate strategy that would serve their country well. Ongeti (2014) states that in Kenya since independence to the recent past TMT of PEs have been political tools, TMTs have in the past been politically appointed into such positions hence productivity of PEs have been very low. Ongeti (2015) further observes that merging and dissolving of some PEs as recommended in the PTPR (2013) would bring about managerial economies of scale and this can improve performance in future.

The effect of TMT demographics on organizational performance may be moderated or intervened by other factors. For instance, Mutuku, K'Obonyo and Awino (2013), TMT Characteristics on Performance of Commercial Banks in Kenya was conceptualized to be moderated by quality of decisions. Also according to Finkelstein and Hambrick (1996) top management demographics offer good prediction of organizational outcomes in direct proportion to how much managerial discretion exists.

TMT demographics have a great influence on which decisions are adopted for corporate strategy mapping which eventually affects organizational performance (Papadakis \& Barwise, 2002). However, effectiveness of top management demographics differs from sector to sector and from organization to organization resulting to variations in organizational performance. This study adopted the Sustainable Balanced Score Card (SBSC) measure of performance. SBSC measure of performance (Hubbard, 2009) is a comprehensive measure that cuts across all the PEs as we have both commercial and non-commercial PEs. SBSC performance indicators include financial performance on budget discipline; customer/ customer service index that advocates for dynamic service delivery; internal business processes in terms of efficiency and effectiveness; organizational learning and growth that leads to zero tolerance to corruption; social responsiveness involving programs that seek to improve on welfare of the communities around where they operate, and environmental integrity that leads to environmental sustainability for example investment in renewable sources of energy.

Bucic and Gudergan (2004) link an organization's strategy to its structure and performance by arguing that organizational structure has a direct effect in the success of its operation strategy. Adewale (2015) argues that proper organizational structure influences and defines the corporate strategy that in turn leads to achievement of its objectives and lastly affects the performance.

\subsection{Kenyan Public Enterprises}

Worldwide, governments have established Public Enterprises (PEs) with expectation that they would play an important economic role. However, evidence drawn from a number of countries between the 1970s and 1980s indicates that PEs have performed poorly on average, relative to private firms. The poor performance of PEs has been partly attributed to multiple policy goals which proved difficult to reconcile. The historical evidence shows that substantial financial losses incurred by PEs subjected the national budgets and banking systems to unsustainable burdens (World Bank, 2014).

Kenyan PEs are institutions or businesses owned by the government either fully or as a majority shareholder. They are formed by the Kenyan government to meet both social and commercial needs while some exist to correct for market failures. According to Presidential Taskforce on Parastatal Reforms [PTPR] (2013), performance of PEs may be directly influenced by TMT demographics. However, due to variations in the specific TMTs demographics among PEs, they may adopt different dimensions of corporate strategy thus creating variation in organizational performance. PEs do not operate in isolation but operate in an environment whose factors they cannot control. Variations in TMT demographics may lead to differences in the type of organizational structure and hence influencing the nature of corporate strategy adopted by organizations thus bringing about variations in performance amongst organizations. Kenyan PEs are important unit of analysis to be studied as they are key to realization of vision 2030, are key to improvement of service delivery and are key to the overall economic development as they contribute to the gross domestic product (GDP) of Kenya.

\subsection{Conceptual Hypothesis}

TMT demographics, corporate strategy and organizational structure jointly have significant effect on the performance of Kenyan PEs. 


\section{Methods}

Data was collected using a semi-structured questionnaire. The questionnaire comprised of both closed and open ended questions guided by the concepts of the study, theory and other previous studies.

The study's respondents were Chief Executive Officers (CEOs) of 117 Kenyan PEs. The key respondents were used because they were conversant with the strategic issues affecting those organizations.

\section{Results}

Computation of composite indices of TMT demographics, corporate strategy, organizational structure and organizational performance was done in order to establish the joint effect of TMT demographics, corporate strategy, and organizational structure on organizational performance. The joint effect was stated and tested as Hypothesis: TMT demographics, corporate strategy and organizational structure jointly have significant effect on performance. The results of the analysis done to determine the joint effect of TMT demographics, corporate strategy, and organizational structure on organizational performance of Kenyan PEs are shown in Table 1.

Table 1. Effects of TMT Demographics, Corporate Strategy, Organizational Structure and Performance

\begin{tabular}{|c|c|c|c|c|c|c|c|c|c|c|}
\hline \multicolumn{11}{|c|}{ Model Summary } \\
\hline Model & \multicolumn{3}{|c|}{$\mathrm{R}$} & \multicolumn{2}{|l|}{ R Square } & \multicolumn{2}{|c|}{ Adjusted R Square } & \multicolumn{3}{|c|}{ Std. Error of the Estimate } \\
\hline dimension & 1 & $.757^{\mathrm{a}}$ & & .573 & & .553 & & & 257 & \\
\hline \multicolumn{11}{|l|}{ ANOVA $^{b}$} \\
\hline Model & & & \multicolumn{2}{|c|}{ Sum of Squares } & \multicolumn{2}{|l|}{$\mathrm{df}$} & Mean Square & \multicolumn{2}{|c|}{$\mathrm{F}$} & Sig. \\
\hline \multirow[t]{3}{*}{1} & & Regression & \multicolumn{2}{|c|}{10.064} & \multicolumn{2}{|l|}{3} & 3.355 & \multirow{2}{*}{\multicolumn{2}{|c|}{28.586}} & $.000^{\mathrm{a}}$ \\
\hline & & Residual & \multicolumn{2}{|c|}{7.511} & \multicolumn{2}{|l|}{64} & .117 & & & \\
\hline & & Total & & & 67 & & & & & \\
\hline \multicolumn{11}{|c|}{ Coefficients $^{\mathrm{a}}$} \\
\hline \multirow[t]{3}{*}{ Model } & & & \multicolumn{2}{|c|}{ Unstandardized } & \multicolumn{3}{|c|}{ Standardized } & & & \\
\hline & & & \multicolumn{2}{|c|}{ Coefficients } & \multicolumn{3}{|c|}{ Coefficients } & & \multicolumn{2}{|c|}{ Collinearity Statistics } \\
\hline & & & B & Std. Error & Beta & & $\mathrm{t}$ & Sig. & Tolerance & VIF \\
\hline \multirow[t]{4}{*}{1} & & (Constant) & .394 & .437 & & & .902 & .370 & & \\
\hline & & TMT demographics & .126 & .098 & .116 & & 1.283 & .204 & .812 & 1.232 \\
\hline & & Corporate Strategy & .466 & .087 & .520 & & 5.370 & .000 & .711 & 1.406 \\
\hline & & Organizational Structure & .338 & .100 & .302 & & 3.364 & .001 & .828 & 1.207 \\
\hline
\end{tabular}

a. Predictors: (Constant), TMT demographics, Corporate Strategy, Organizational Structure, Dependent Variable: Organizational Performance.

The results showed the joint effect of TMT demographics, corporate strategy, and organizational structure had a moderately strong positive effect on $(\mathrm{R}=0.757)$ on organizational performance. From the results of analyses the combined effect of TMT demographics, corporate strategy, and organizational structure explained 57.3 percent $\left(\mathrm{R}^{2}=0.573\right)$ of variation in organizational performance with 42.7 percent of organizational performance being accounted for by other factors not considered in the model.

The regression model's F statistic ratio was 28.586 and the calculated p-value was 0.000 . Since the calculated p-value was less than 0.05 , the study failed to reject the hypothesis meaning that TMT demographics, corporate strategy, and organizational structure jointly had a significant effect on organizational performance. This therefore implies that the model was appropriate to measure the hypothesized scenario. Surprisingly, the independent effect of TMT demographics on organizational performance was not statistically significant ( $p$ value $=0.204$ was more than calculated $\mathrm{p}$ value $=0.05$ ). Conversely, the independent effects of corporate strategy and organizational structure on organizational performance were statistically significant ( $\beta=0.466$ and $\beta=0.338$ respectively) and the calculated $p$ values ( 0.000 and 0.001 respectively) were less than 0.05 .

These relationships are presented in the following equations;

$$
\mathrm{OP}=0.394+0.126 \mathrm{TMT}+0.466 \mathrm{CS}+0.338 \mathrm{OS} .
$$

Where $\mathrm{OP}=$ Organizational performance, $\mathrm{TMT}=$ Composite $\mathrm{TMT}$ demographics, $\mathrm{CS}=$ Composite Corporate strategy, OS= Composite Organizational structure.

Equation (1) means that a unit change in TMT demographics yields 0.126 positive change in performance. 
Similarly a unit change of corporate strategy yields 0.466 positive change in organizational performance while a unit change in organizational structure yields 0.338 positive change in performance.

The subsequent section presents results of the independent joint effect of TMT demographics, corporate strategy and organizational structure on each of the six SBSC measures of organizational performance.

Statistical analysis results to establish the joint effect of TMT demographics, corporate strategy, and organizational structure on financial performance are presented in Table 2. TMT demographics was conceptualized as the independent variable, corporate strategy was conceptualized as intervening variable, and organizational structure was conceptualized as the moderating variable. Financial performance which is the first SBSC measure of performance was conceptualized as the dependent variable.

Table 2. TMT Demographics, Corporate Strategy, Organizational Structure and Financial Performance

\begin{tabular}{|c|c|c|c|c|c|c|}
\hline \multicolumn{7}{|c|}{ Model Summary } \\
\hline \multirow{2}{*}{$\frac{\text { Model }}{01}$} & $\mathrm{R}$ & \multicolumn{2}{|l|}{ R Square } & Adjusted R Square & \multicolumn{2}{|c|}{ Std. Error of the Estimate } \\
\hline & $.558^{\mathrm{a}}$ & .312 & & .281 & .50282 & \\
\hline \multicolumn{7}{|c|}{ ANOVA $^{b}$} \\
\hline \multicolumn{2}{|l|}{ Model } & Sum of Squares & df & Mean Square & $\mathrm{F}$ & Sig. \\
\hline \multirow[t]{3}{*}{1} & Regression & 7.784 & 3 & 2.595 & 10.263 & $.000^{\mathrm{a}}$ \\
\hline & Residual & 17.193 & 68 & .253 & & \\
\hline & Total & 24.977 & 71 & & & \\
\hline \multicolumn{7}{|c|}{ Coefficients $^{\mathrm{a}}$} \\
\hline \multirow[t]{3}{*}{ Model } & & & & Standardized & & \\
\hline & & Unstandardized & ficients & Coefficients & & \\
\hline & & $\mathrm{B}$ & Std. Error & Beta & $\mathrm{t}$ & Sig. \\
\hline \multirow[t]{4}{*}{1} & (Constant) & 1.441 & .617 & & 2.335 & .022 \\
\hline & TMT demographics & .106 & .141 & .085 & .756 & .453 \\
\hline & Corporate Strategy & .522 & .127 & .500 & 4.112 & .000 \\
\hline & Organizational Struc & Ire .041 & .145 & .032 & .281 & .779 \\
\hline
\end{tabular}

a. Predictors: (Constant), TMT demographics, Corporate Strategy, Organizational Structure, Dependent Variable: Financial Performance

TMT demographics, Corporate Strategy, and Organizational Structure had mixed effects on financial performance. For example TMT demographics, Corporate Strategy, and Organizational Structure had a positive influence ( $\beta=0.106, \beta=0.522$ and $\beta=0.041$ respectively) on financial performance. Apart from corporate strategy which had a statistically significant influence on financial performance, the calculated $p$ value was less than 0.05, TMT demographics and Organizational Structure influence on financial performance was not statistically significant. The calculated $p$ values ( 0.453 and 0.779 respectively) were greater than 0.05 .

These relationships are represented in the following equations;

$$
\mathrm{FP}=1.441+0.106 \mathrm{TMT}+0.522 \mathrm{CS}+0.041 \mathrm{OS}
$$

Where FP= Financial Performance, $\mathrm{TMT}=$ Composite TMT demographics, $\mathrm{CS}=$ Composite Corporate strategy, $\mathrm{OS}=$ Composite Organizational structure.

In equation (2) a unit change in the constant yields 1.441 positive change in financial performance while a unit change in TMT demographics yields 0.106 positive changes in financial performance. Conversely, a unit change in corporate strategy yields 0.522 positive changes in financial performance, and a unit change in organizational structure yields 0.041 positive changes in financial performance. Only corporate strategy was statistically significant.

Statistical analysis results to establish the joint effect of TMT demographics, corporate strategy, and organizational structure on customer focus performance are presented in Table 2. TMT demographics was conceptualized as the independent variable, corporate strategy was conceptualized as intervening variable, and organizational structure was conceptualized as the moderating variable. Customer focus performance which is the second SBSC measure of performance was conceptualized as the dependent variable. 
Table 3. Effects of TMT Demographics, Corporate Strategy, Organizational Structure and Customer Focus Performance

\begin{tabular}{|c|c|c|c|c|c|c|}
\hline \multicolumn{7}{|c|}{ Model Summary } \\
\hline \multirow{2}{*}{$\begin{array}{ll}\text { Model } \\
01\end{array}$} & $\mathrm{R}$ & R Square & \multicolumn{2}{|c|}{ Adjusted R Square } & \multicolumn{2}{|c|}{ Std. Error of the Estimate } \\
\hline & $.732^{\mathrm{a}}$ & .536 & & & .48364 & \\
\hline \multicolumn{7}{|c|}{ ANOVA $^{b}$} \\
\hline \multicolumn{2}{|c|}{ Model } & Sum of Squares & df & Mean Square & $\mathrm{F}$ & Sig. \\
\hline \multirow[t]{3}{*}{1} & Regression & 19.179 & 3 & 6.393 & 27.332 & $.000^{\mathrm{a}}$ \\
\hline & Residual & 16.607 & 71 & .234 & & \\
\hline & Total & 35.787 & 74 & & & \\
\hline \multicolumn{7}{|c|}{ Coefficients $^{\mathrm{a}}$} \\
\hline \multirow[t]{3}{*}{ Model } & & & & Standardized & & \\
\hline & & Unstandardized & ficients & Coefficients & & \\
\hline & & $\mathrm{B}$ & Std. Error & Beta & $\mathrm{t}$ & Sig. \\
\hline \multirow[t]{4}{*}{1} & (Constant) & -.621 & .588 & & -1.056 & .294 \\
\hline & TMT demographics & .027 & .135 & .018 & .200 & .842 \\
\hline & Corporate Strategy & .726 & .122 & .582 & 5.972 & .000 \\
\hline & Organizational Struc & ure .375 & .137 & .246 & 2.726 & .008 \\
\hline \multicolumn{7}{|c|}{$\begin{array}{l}\text { a. Predictors: (Constant), TMT demographics, Corporate Strategy, Organizational Structure, } \\
\text { b. Dependent Variable: Customer Focus Performance }\end{array}$} \\
\hline
\end{tabular}

From the results in Table 3 the joint effect of TMT demographics, corporate strategy, and organizational structure had a strong positive relationship $(\mathrm{R}=0.732)$ on customer focus performance. The research findings indicate that the joint effect of TMT demographics, corporate strategy, and organizational structure explains 53.6 percent of variation in customer focus performance $\left(\mathrm{R}^{2}=0.536\right)$. This means 46.4 percent of variation in customer focus performance is explained by other factors not accounted in the model. The F statistic of the model was 27.332 and $p$ value was 0.000 . The calculated $p$ value was less than 0.05 and hence statistically significant at 95 percent confidence level. This means that the model was appropriate to measure the hypothesized scenario. This relationship is represented in the following equation:

$$
\mathrm{CF}=-0.621+0.027 \mathrm{TMT}+0.726 \mathrm{CS}+0.375 \mathrm{OS}
$$

Where $\mathrm{CF}=$ Customer focus performance, $\mathrm{TMT}=$ Composite $\mathrm{TMT}$ demographics, $\mathrm{CS}=$ Composite Corporate strategy, OS= Composite Organizational structure

In equation (3) a unit change in the constant yields - 0.621 negative change of customer focus performance while a unit change in TMT demographics yields to 0.027 positive change in customer focus performance. Additionally, a unit change in corporate strategy yields 0.726 positive changes in customer focus performance while a unit change in organizational structure yields 0.375 positive changes in customer focus performance. Corporate strategy and organizational structure were statistically significant independently.

Statistical analysis results to establish the joint effect of TMT demographics, corporate strategy, and organizational structure on internal business processes performance are presented in Table 4. TMT demographics was conceptualized as the independent variable, corporate strategy was conceptualized as intervening variable, and organizational structure was conceptualized as the moderating variable. Internal business processes performance which is the third SBSC measure of performance was conceptualized as the dependent variable. 
Table 4. Effects of TMT Demographics, Corporate Strategy, Organizational Structure and Internal Business Processes Performance

\begin{tabular}{|c|c|c|c|c|c|c|}
\hline \multicolumn{7}{|c|}{ Model Summary } \\
\hline \multicolumn{2}{|l|}{ Model } & $\mathrm{R}$ & R Square & \multirow{2}{*}{$\begin{array}{l}\text { Adjusted R Square } \\
.380\end{array}$} & \multicolumn{2}{|c|}{ Std. Error of the Estimate } \\
\hline dimension & 1 & & & & .4614 & \\
\hline \multicolumn{7}{|l|}{ ANOVA $^{\mathrm{b}}$} \\
\hline Model & & Sum of Squares & df & Mean Square & $\mathrm{F}$ & Sig. \\
\hline \multirow[t]{3}{*}{1} & Regression & 10.034 & 3 & 3.345 & 15.705 & $.000^{\mathrm{a}}$ \\
\hline & Residual & 14.695 & 69 & .213 & & \\
\hline & Total & 24.730 & 72 & & & \\
\hline \multicolumn{7}{|c|}{ Coefficients ${ }^{\mathrm{a}}$} \\
\hline \multirow[t]{3}{*}{ Model } & & & & Standardized & & \\
\hline & & Unstandardize & ficients & Coefficients & & \\
\hline & & $\mathrm{B}$ & Std. Error & Beta & $\mathrm{t}$ & Sig. \\
\hline \multirow[t]{4}{*}{1} & (Constant) & .749 & .576 & & 1.300 & .198 \\
\hline & TMT demographics & .059 & .131 & .046 & .450 & .654 \\
\hline & Corporate Strategy & .524 & .116 & .501 & 4.516 & .000 \\
\hline & Organizational Struc & .263 & .132 & .204 & 1.991 & .050 \\
\hline
\end{tabular}

a. Predictors: (Constant), TMT demographics, Corporate Strategy, Organizational Structure, Dependent Variable: Internal Business Processes performance

From results in Table 4 the joint effect of TMT demographics, corporate strategy, and organizational structure had a strong positive relationship $(\mathrm{R}=0.637)$ on internal business processes performance. The research findings indicate that the joint effect of TMT demographics, corporate strategy, and organizational structure explains 40.6 percent of variation in internal business processes performance $\left(\mathrm{R}^{2}=0.406\right)$. This means 59.4 percent of variation in internal business processes performance is explained by other factors not accounted in the model. The F statistic of the model was 15.705 and $p$ value was 0.000 . The calculated $p$ value was less than 0.05 and hence statistically significant at 95 percent confidence level. This means that the model was appropriate to measure the hypothesized scenario. This relationship is represented in the following equation:

$$
\mathrm{IBP}=0.749+0.059 \mathrm{TMT}+0.524 \mathrm{CS}+0.263 \mathrm{OS} .
$$

Where IBP $=$ Internal business processes performance, $\mathrm{TMT}=$ Composite $\mathrm{TMT}$ demographics, $\mathrm{CS}=\mathrm{Composite}$ Corporate strategy, $\mathrm{OS}=$ Composite Organizational structure

In equation (4) a unit change in the constant yields 0.749 positive change of internal business processes performance while a unit change in TMT demographics yields to 0.059 positive changes in internal business processes performance. Additionally, a unit change in corporate strategy yields 0.524 positive changes in internal business processes performance while a unit change in organizational structure yields 0.263 positive changes in internal business processes performance.

Statistical analysis results to establish the joint effect of TMT demographics, corporate strategy, and organizational structure on organizational learning and growth performance are presented in Table 5. TMT demographics was conceptualized as the independent variable, corporate strategy was conceptualized as intervening variable, and organizational structure was conceptualized as the moderating variable. Organizational learning and growth performance which is the fourth SBSC measure of performance was conceptualized as the dependent variable. 
Table 5. Effects of TMT Demographics, Corporate Strategy, Organizational Structure and Organizational Learning and Growth Performance

\begin{tabular}{|c|c|c|c|c|c|c|}
\hline \multicolumn{7}{|c|}{ Model Summary } \\
\hline \multirow{2}{*}{$\begin{array}{l}\text { Model } \\
01\end{array}$} & $\mathrm{R}$ & R Square & \multicolumn{2}{|c|}{ Adjusted R Square } & \multicolumn{2}{|c|}{ Std. Error of the Estimate } \\
\hline & $.533^{\mathrm{a}}$ & .284 & & & .69352 & \\
\hline \multicolumn{7}{|c|}{ ANOVA $^{b}$} \\
\hline \multicolumn{2}{|c|}{ Model } & Sum of Squares & $\mathrm{df}$ & Mean Square & $\mathrm{F}$ & Sig. \\
\hline \multirow[t]{3}{*}{1} & Regression & 13.755 & 3 & 4.585 & 9.532 & $.000^{\mathrm{a}}$ \\
\hline & Residual & 34.630 & 72 & .481 & & \\
\hline & Total & 48.385 & 75 & & & \\
\hline \multicolumn{7}{|c|}{ Coefficients $^{\mathrm{a}}$} \\
\hline \multirow[t]{3}{*}{ Model } & & & & Standardized & & \\
\hline & & Unstandardized & fficients & Coefficients & & \\
\hline & & $\mathrm{B}$ & Std. Error & Beta & $\mathrm{t}$ & Sig. \\
\hline \multirow[t]{4}{*}{1} & (Constant) & -.302 & .836 & & -.362 & .719 \\
\hline & TMT demographics & .276 & .193 & .161 & 1.430 & .157 \\
\hline & Corporate Strategy & .398 & .174 & .277 & 2.290 & .025 \\
\hline & Organizational Struc & re .434 & .197 & .246 & 2.202 & .031 \\
\hline \multicolumn{7}{|c|}{$\begin{array}{l}\text { a. Predictors: (Constant), TMT demographics, Corporate Strategy, Organizational Structure, } \\
\text { b. Dependent Variable: Organizational Learning and Growth performance }\end{array}$} \\
\hline
\end{tabular}

Predictors: (Constant), TMT demographics, Corporate Strategy, Organizational Structure, Dependent Variable: Organizational Learning and Growth performance.

From results in Table 5 the joint effect of TMT demographics, corporate strategy, and organizational structure had a moderate positive relationship $(\mathrm{R}=0.533)$ on Organizational learning and growth performance. The research findings indicate that the joint effect of TMT demographics, corporate strategy, and organizational structure explains 28.4 percent of variation in Organizational learning and growth performance $\left(\mathrm{R}^{2}=0.284\right)$. This means 71.6 percent of variation in Organizational learning and growth performance is explained by other factors not accounted in the model. The F statistic of the model was 9.532 and $p$ value was 0.000 . The calculated $\mathrm{p}$ value was less than 0.05 and hence statistically significant at 95 percent confidence level. This means that the model was appropriate to measure the hypothesized scenario. This relationship is represented as follows:

$$
\mathrm{OLG}=-0.302+0.276 \mathrm{TMT}+0.398 \mathrm{CS}+0.434 \mathrm{OS} \text {. }
$$

Where $\mathrm{OLG}=$ Organizational learning and growth performance, $\mathrm{TMT}=$ Composite TMT demographics, $\mathrm{CS}=$ Composite Corporate strategy, $\mathrm{OS}=$ Composite Organizational structure

In equation (5) a unit change in the constant yields -0.302 negative change of organizational learning and growth performance while a unit change in TMT demographics yields to 0.276 positive change in organizational learning and growth performance. Additionally, a unit change in corporate strategy yields 0.398 positive changes in organizational learning and growth performance while a unit change in organizational structure yields 0.434 positive changes in organizational learning and growth performance.

Statistical analysis results to establish the joint effect of TMT demographics, corporate strategy, and organizational structure on social responsiveness performance are presented in Table 6. TMT demographics was conceptualized as the independent variable, corporate strategy was conceptualized as intervening variable, and organizational structure was conceptualized as the moderating variable. Social responsiveness performance which is the fifth SBSC measure of performance was conceptualized as the dependent variable. 
Table 6. Effects of TMT demographics, Corporate Strategy, Organizational Structure and Social Responsiveness Performance

\begin{tabular}{|c|c|c|c|c|c|c|}
\hline \multicolumn{7}{|c|}{ Model Summary } \\
\hline \multicolumn{2}{|c|}{ Model } & $\mathrm{R}$ & \multirow{2}{*}{$\begin{array}{l}\text { R Square } \\
.392\end{array}$} & \multirow{2}{*}{$\begin{array}{l}\text { Adjusted R Square } \\
.367\end{array}$} & \multicolumn{2}{|c|}{ Std. Error of the Estimate } \\
\hline dimension & 1 & $.626^{\mathrm{a}}$ & & & .490 & \\
\hline \multicolumn{7}{|l|}{ ANOVA $^{b}$} \\
\hline Model & & Sum of Squares & $\mathrm{df}$ & Mean Square & $\mathrm{F}$ & Sig. \\
\hline \multirow[t]{3}{*}{1} & Regression & 11.177 & 3 & 3.726 & 15.491 & $.000^{\mathrm{a}}$ \\
\hline & Residual & 17.316 & 72 & .241 & & \\
\hline & Total & 28.493 & 75 & & & \\
\hline \multicolumn{7}{|c|}{ Coefficients $^{\mathrm{a}}$} \\
\hline \multirow[t]{3}{*}{ Model } & & & & Standardized & & \\
\hline & & Unstandardized & Coefficients & Coefficients & & \\
\hline & & $\mathrm{B}$ & Std. Error & Beta & $\mathrm{t}$ & Sig. \\
\hline \multirow[t]{4}{*}{1} & (Constant) & .645 & .591 & & 1.091 & .279 \\
\hline & TMT demographics & .051 & .137 & .039 & .377 & .707 \\
\hline & Corporate Strategy & .356 & .123 & .323 & 2.897 & .005 \\
\hline & Organizational Stru & cture .533 & .139 & .393 & 3.827 & .000 \\
\hline
\end{tabular}

a. Predictors: (Constant), TMT demographics, Corporate Strategy, Organizational Structure, Dependent Variable: Social Responsiveness Performance.

From results in Table 6 the joint effect of TMT demographics, corporate strategy, and organizational structure had a strong positive relationship $(\mathrm{R}=0.626)$ on social responsiveness performance. The research findings indicate that the joint effect of TMT demographics, corporate strategy, and organizational structure explains 39.2 percent of variation in social responsiveness performance $\left(R^{2}=0.392\right)$. This means 60.8 percent of variation in social responsiveness is explained by other factors not accounted in the model. The F statistic of the model was 15.491 and $p$ value was 0.000 . The calculated $p$ value was less than 0.05 and hence statistically significant at 95 percent confidence level. This means that the model was appropriate to measure the hypothesized scenario. This relationship is represented in the following equation:

$$
\mathrm{SR}=0.645+0.051 \mathrm{TMT}+0.356 \mathrm{CS}+0.533 \mathrm{OS} \text {. }
$$

Where $\mathrm{SR}=$ Social responsiveness performance, $\mathrm{TMT}=$ Composite $\mathrm{TMT}$ demographics, $\mathrm{CS}=$ Composite Corporate strategy, $\mathrm{OS}=$ Composite Organizational structure

In equation (6) a unit change in the constant yields 0.645 positive change of social responsiveness performance while a unit change in TMT demographics yields to 0.051 positive changes in social responsiveness performance. Additionally, a unit change in corporate strategy yields 0.356 positive changes in social responsiveness performance while a unit change in organizational structure yields 0.533 positive changes in social responsiveness performance.

Statistical analysis results to establish the joint effect of TMT demographics, corporate strategy, and organizational structure on environmental integrity performance are presented in Table 7. TMT demographics was conceptualized as the independent variable, corporate strategy was conceptualized as intervening variable, and organizational structure was conceptualized as the moderating variable. Environmental integrity performance which is the sixth and final SBSC measure of performance was conceptualized as the dependent variable. 
Table 7. Effects of TMT Demographics, Corporate Strategy, Organizational Structure and Environmental Integrity Performance

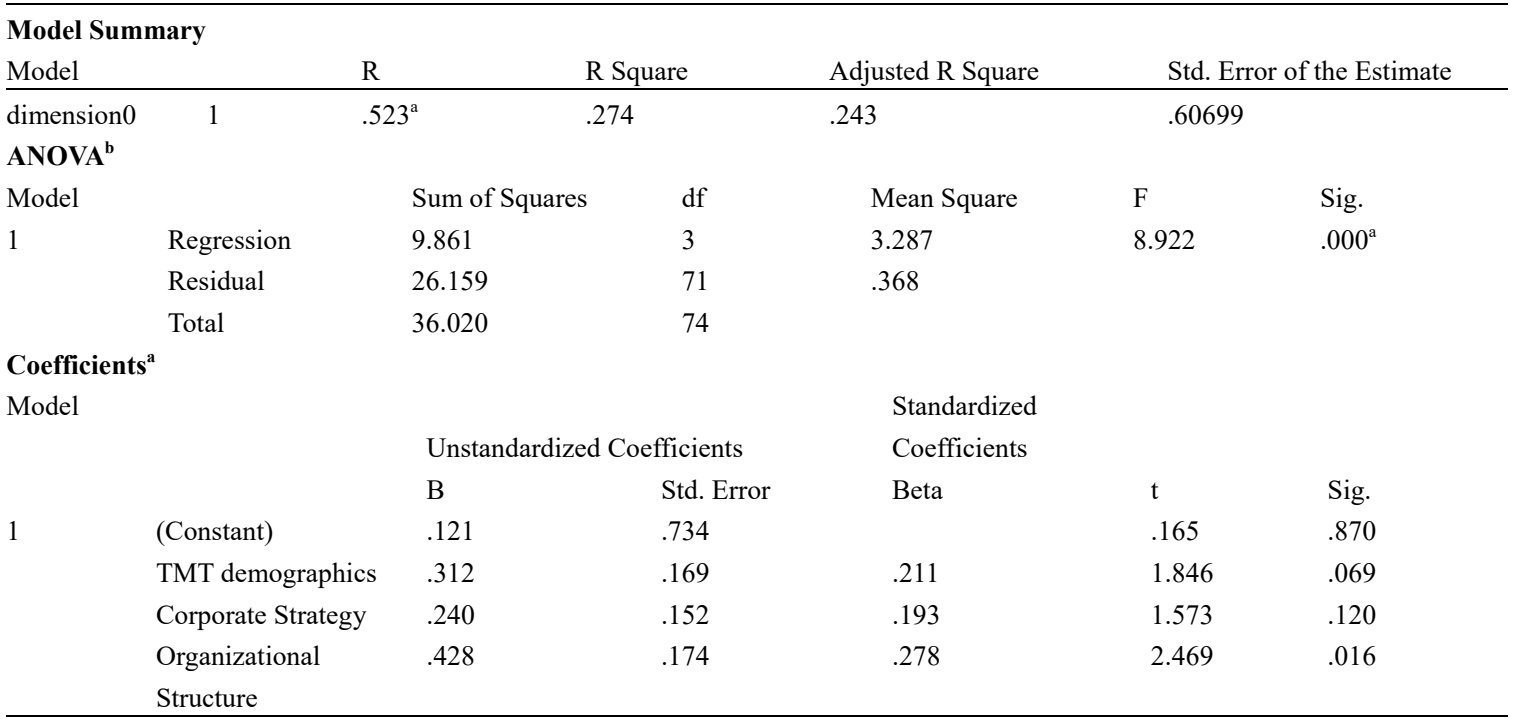

Predictors: (Constant), TMT demographics, Corporate Strategy, Organizational Structure, Dependent Variable: Environmental Integrity Performance.

From results in Table 7 the joint effect of TMT demographics, corporate strategy, and organizational structure had a moderate positive relationship $(\mathrm{R}=0.523)$ on environmental integrity performance. The research findings indicate that the joint effect of TMT demographics, corporate strategy, and organizational structure explains 27.4 percent of variation in environmental integrity performance $\left(R^{2}=0.274\right)$. This means 72.6 percent of variation in environmental integrity is explained by other factors not accounted in the model. The $\mathrm{F}$ statistic of the model was 8.922 and $p$ value was 0.000 . The calculated $p$ value was less than 0.05 and hence statistically significant at 95 percent confidence level. This means that the model was appropriate to measure the hypothesized scenario. This relationship is represented in the following equation:

$$
\mathrm{EI}=0.121+0.312 \mathrm{TMT}+0.240 \mathrm{CS}+0.428 \mathrm{OS} \text {. }
$$

Where EI $=$ Environmental integrity performance, $\mathrm{TMT}=$ Composite $\mathrm{TMT}$ demographics, $\mathrm{CS}=$ Composite Corporate strategy, $\mathrm{OS}=$ Composite Organizational structure

In equation (7) a unit change in the constant yields 0.121 positive change of environmental integrity performance while a unit change in TMT demographics yields to 0.312 positive change in environmental integrity performance. Additionally, a unit change in corporate strategy yields 0.240 positive changes in environmental integrity performance while a unit change in organizational structure yields 0.428 positive changes in environmental integrity performance.

\section{Conclusion}

The objective of the study sought to establish the joint effect of TMT demographics, corporate strategy, and organizational structure on organizational performance. The joint effect was stated and tested as Hypothesis: TMT demographics, corporate strategy and organizational structure jointly have significant effect on the performance of Kenyan PEs.

This combination is consistent with an argument by Doz and Kosonen (2007) who indicated that the relationship between top management team demographic characteristics and performance need consideration of other contextual factors like corporate strategy which must be considered when investigating TMT demographic characteristics- performance relationship. The results showed that the joint effect of TMT demographics, corporate strategy, and organizational structure had a moderately strong positive effect $(\mathrm{R}=0.757)$ on organizational performance. The combined effect of TMT demographics, corporate strategy, and organizational structure explained 57.3 percent $\left(\mathrm{R}^{2}=0.573\right)$ of variation in organizational performance with 42.7 percent of organizational performance being accounted for by other factors not considered in the model.

The regression model's F statistic ratio was 28.586 and the calculated p-value was 0.000 and since the calculated p-value was less than 0.05 , the study failed to reject the hypothesis meaning that TMT demographics, corporate 
strategy, and organizational structure jointly had a significant effect on organizational performance. On the other hand, the independent effect of TMT demographics on organizational performance was not statistically significant ( $\mathrm{p}$ value $=0.204$ was more than calculated $\mathrm{p}$ value $=0.05$ ).

Conversely, the independent effects of corporate strategy and organizational structure on organizational performance was statistically significant $(\beta=0.466$ and $\beta=0.338$ respectively) and the calculated $p$ values $(0.000$ and 0.001 respectively) were less than 0.05 . The findings imply that a unit change in TMT demographics yields 0.126 positive change of performance. Similarly a unit change of corporate strategy yields 0.466 positive changes in organizational performance while a unit change in organizational structure yields 0.338 positive changes in performance. The study further established independent joint effect of TMT demographics, corporate strategy and organizational structure on each of the six SBSC measures of organizational performance.

This finding is consistent with Harris and Ruefli (2000) who indicated that organizational structure and corporate strategy have a mutual relationship and that they influence organization performance positively. According to the scholars, processes that turn organizational strategies into action, commonly known as "operationalization," "implementation of strategies," or "strategy doing," unfold through organizational structures and organizational activities. Strategies are put into effect through organizational structures and behaviour and that ultimately affects performance.

With regard to financial performance, the results revealed that TMT demographics, Corporate Strategy, and Organizational Structure had mixed effects on financial performance. TMT demographics, Corporate Strategy, and Organizational Structure had a positive influence $(\beta=0.085, \beta=0.500$ and $\beta=0.032$ respectively) on financial performance and only corporate strategy had a statistically significant influence. The study findings also indicated that the joint effect of TMT demographics, corporate strategy, and organizational structure had a strong positive relationship $(\mathrm{R}=0.732)$ on customer focus. The research findings indicate that the joint effect of TMT demographics, corporate strategy, and organizational structure explains 53.6 percent of variation in customer focus performance $\left(\mathrm{R}^{2}=0.536\right)$.

The results were also mixed as was the case with financial performance as it was established that a unit change in TMT demographics yields to 0.027 positive change in customer focus performance, a unit change in corporate strategy yields 0.726 positive change in customer focus performance while a unit change in organizational structure yields 0.375 positive change in customer focus performance. Only corporate strategy and organizational structure had a significant effect on customer focus performance.

The findings on organizational learning and growth showed that the joint effect of TMT demographics, corporate strategy, and organizational structure had a moderate positive relationship $(\mathrm{R}=0.533)$ on organizational learning and growth performance explaining 28.4 percent of variation in organizational learning and growth performance $\left(\mathrm{R}^{2}=0.284\right)$. The results also indicated that only corporate strategy and organizational structure had a significant effect on organizational learning and growth performance. The results also showed that the joint effect of TMT demographics, corporate strategy, and organizational structure had a strong positive relationship $(R=0.626)$ on social responsiveness performance as well as on environmental integrity performance $(R=0.523)$. The joint effect of TMT demographics, corporate strategy, and organizational structure explains 39.2 percent of variation in social responsiveness performance $\left(\mathrm{R}^{2}=0.392\right)$ and 27.4 percent of variation in environmental integrity performance $\left(\mathrm{R}^{2}=0.274\right)$. Only corporate strategy and organizational structure had a significant effect on social responsiveness and only organizational structure had a significant effect on environmental integrity performance.

The findings are consistent with an argument by Schein (1985) that corporate strategies influence the interaction between organization structures and behaviour and vice versa. The argument is that "espoused values" have an impact on "artefacts," which in turn influence "espoused values." As organizational structures as well as behaviour were identified as elements of organizational artefacts, both are affected by strategy. The findings also support the argument by Chandler's (1962) who empirically observed that organizations, after changes in strategies, suffered from a phase of ineffectiveness. However, after structural changes were achieved, organizations started to become more profitable again proving that corporate strategy affects performance positively.

The findings are also consistent with Finkelstein et al (2009) who observed that globally out of every ten PEs eight have a diverse TMT that influences which corporate strategy to adopt and on the other hand TMT is highly influenced by the organizational structure in place because an organizational structure commands the flow of information among the TMT and that influences organization performance significantly. The results are also consistent with Akinyele (2011); Lavie's (2006); Grewal and Tansuhaj (2001) who indicated that the organizational structure and strategies adopted by companies affect market share positively. 


\subsection{Contribution of Study to New Knowledge}

Perhaps the biggest implication of this study was its attempt to enhance an empirical and conceptual discourse on the relationship between theories that inform TMT demographics, corporate strategy as well as organizational structure and organizational performance. It is hoped that the findings of this study will promote not only a deeper conceptual but rather theoretical debate on how to link the two divides.

The upper echelons theory anchors the interface of TMT demographics and performance as it postulates that strategic decisions and the performance levels of organizations are partially predicted by management demographics. Configuration and institutional theories determine the interaction between strategy and structure. They explain how TMT demographics, corporate strategy and organizational structure are configured into a synergetic whole to produce stellar performance whereas behavioural theory centres on the discretion of TMTs in corporate strategy generation and implementation based on what type of structure they adopt.

Perhaps the most intriguing finding of the study was the independent positive effects of TMT demographics that were not statistically significant though the overall joint effect was significant in all scenarios tested. All the variables influenced performance positively. This could have been likely informed by the appointment process, frequent changes and challenges that surface from PEs. This is a debate that should continue beyond this study.

\subsection{Limitations of the Study}

Conceptually, the study variables used in the study to predict performance in PEs were TMT demographics, corporate strategy and organizational structure; however, these three variables do not describe the totality of the variables that influence performance in PEs. Literature has proven that organizational performance could also be influenced by other factors including corporate governance, ownership structure, resource allocation, the external environment, systems (for example technology, policies and procedures), organizational culture, employee motivation, needs and job fit. All these factors were not considered in this study. This opens a gap for other studies to focus on.

Contextually, this study was undertaken within the Kenyan PEs only. PEs operate in very different internal and external environments from other organizations like the private sector. The results therefore must be used cautiously because they may not be easily generalized in other sectors like the manufacturing sector, transport sector and so on. This is because organizations in the private sector operate in a different environment. Probably the results of this study would have been conflicting if the study was conducted in organizations within the private sector.

Methodological limitations were also experienced. The study used a descriptive cross sectional survey design. This research design does not delve into details of the factors that are being examined. The results of the study could probably have been different if for example an explanatory or a longitudinal research design was used. A longitudinal research design for instance takes more time and the changes that occur during the course of the study could have affected the findings.

Arising from the limitations, there is need to regard leadership and culture as moderating variables in the studies concerning demographic characteristics and performance and compare the findings with those of the current study. The Kenyan PEs are heavily influenced by cultural background issues; this therefore presents a new knowledge gap for future studies to focus on.

\section{References}

Adewale, O. F., \& Elumah, L. O. (2015). The influence of organizational structure on job performance (A Study of Universities in Nigeria)

Akinyele, S. T. (2011). Significance of strategic marketing to enterprise performance: An empirical analysis of Nigerian oil and gas industry, Global Journal of Management and Business Research, 10(6), 60-77.

Andrews, K. (1980). The concept of corporate strategy (2nd ed.). Irwin, Dow-Jones.

Awino, Z. B. (2013a). An empirical study of top management team diversity, and performance in the service industry. Journal in Organizational Psychology and Educational Studies, 2(1), 25-31.

Awino, Z. B. (2013b). Top management team diversity, quality decisions and organizational performance in the service industry. Journal of Management and Strategy, 4(1), 113.

Bagire, V. (2012). Strategic configurations and performance of large non-governmental organizations in Uganda. (Unpublished PhD thesis), University of Nairobi.

Bucic, T., \& Gudergan, S. (2004). The impact of organizational settings on creativity and learning in alliances, 
Management, 7, 257-273.

Burns, T. and Stalker, G.M. (1961). The management of innovation. London: Tavistock.

Carpenter, M. A., \& Fredrickson, J. W. (2013). Top management teams, global strategic posture, and the moderating role of uncertainty. Academy of Management Journal, 44(3), 533-545.

Chandler, A. D. (1962a). Strategy and structure. Cambridge, MA: MIT Press.

Chandler, A. D. (1962b). Strategy and structure: chapters in the history of American industrial enterprise. Cambridge, M.A.: MIT Pres.

Cyert, R. \& March, J. (1963). The Behavioural Theory of the Firm. Englewood Cliffs, NJ, Prentice Hall.

Desai, V. M. (2016). The behavioural theory of the (governed) firm: corporate board influences on organizations' responses to performance shortfalls. Academy of Managerial Journal, 59(3), 860-879. https://doi.org/10.5465/amj.2013.0948.

Doz, Y. L. \& Kosonen, M. (2007). Embedding strategic agility: a leadership agenda for accelerating business model renewal. Long Range Planning, 43, 370-382.

Finkelstein, S., \& Hambrick, D. C. (1996). Strategic leadership: top executives and their effects on organizations. Minneappolis, West Publishing.

Finkelstein, S., Hambrick, D. C., \& Cannella, A. A. (2009). Strategic leadership: theory and research on executives, top management teams, and boards. Oxford University Press.

Grewal, R., \& Tansuhaj, P. (2001). Building organizational capabilities for managing economic crisis: the role of market orientation and strategic management, Journal of Marketing, 65, 67-80. https://doi.org/10.1509/jmkg.65.2.67.18259.

Hambrick, D. C., \& Mason, P. A. (1984). Upper echelons: the organization as a reflection of its top managers. Academy of Management Review, 9(2), 193-206. http://dx.doi.org/10.2307/258434.

Harris, I. C., \& Ruefli, T. W. (2000). The strategy-structure debate: an examination of the performance implications. Journal of Management Studies, 37, 587-604.

Hubbard, G. (2009). Measuring firm's performance: beyond the triple bottom line. Business Strategy and the Environment, 19, 177-191. https://doi.org/10.1002/bse.564.

Hunter, S. D. (2015). Combining theoretical perspectives on the organization structure-performance relationship. Journal of Organization Design, 4(2), 24-37.

Kasomi, F. M. (2015). Diversity in top management, strategy, top managers' compensation and performance of Kenyan state corporations. (Unpublished PhD thesis), University of Nairobi.

Kondra, A. Z., \& Hinings, C. R. (1998). Organizational diversity and change in institutional theory. Organization Studies, 19(5), 743-769.

Lavie, D. (2006). Capability reconfiguration: an analysis of incumbent responses to technology change, Academy of Management Executive, $\quad 31(1), \quad$ 152-174. http://citeseerx.ist.psu.edu/viewdoc/download?doi=10.1.1.452.6212\&rep=rep1\&type=pdf.

Miller, D., \& Friesen, P. H. (1984). Organizations: A quantum view. Englewood-Cliffs, N.J., Prentice-Hall. https://doi.org/10.1086/228372.

Mkalama, R. N. (2014). Top management demographics, strategic decision making, macro-environment and performance of Kenyan state corporations. (Unpublished PhD thesis), University of Nairobi.

Munyoki, C. (2015). Competitive strategies, organizational autonomy, positioning and performance of Kenyan state corporations. (Unpublished PhD thesis), University of Nairobi.

Mutuku, C., K’Obonyo, P., \& Awino, Z. B. (2013). Top management team diversity, quality of decisions and performance of commercial banks in Kenya. Asian Journal of Humanities and Social Sciences (AJHSS), 1(3), 205-218.

Nielsen, B. B., \& Nielsen, S. (2011). The role of top management team international orientation in international strategic decision-making: the choice of foreign entry. Strategic Management Journal, 26(3), 301-316.

Nielsen, B. B., \& Nielsen, S. (2013). Top management team nationality diversity and firm performance: A multilevel study. Strategic Management Journal, 34(3), 373-382. https://doi.org/10.1002/smj.2021. 
Nielsen, S. (2010). Top management team diversity. a review of theories and methodologies. International Journal of Management Reviews, 26(3), 301-316.

Nyangau, J. Z. (2015). Higher education as an instrument of economic growth in Kenya. Forum for International Research (FIRE), 1(1), 7-25.

Ongeti, W. J. (2014). Organizational resources, corporate governance structures and performance of Kenyan state corporations. (Unpublished PhD thesis), University of Nairobi.

Papadakis, V. M., \& Barwise, P. (2002). How much do CEOs and top managers matter in strategic decision making? British Journal of Management, 1(13), 83-95. https://doi.org/10.1111/1467-8551.00224.

Pearce II, J. A., Robinson, R. B., \& Mital, A. (2012). Strategic Management: formulation, implementation and control (12th ed.). New Delhi, Tata McGraw Hill Education.

PTPR (2013). Report of the presidential taskforce on parastatal reforms. Retrieved at http://www.apsea.or.ke/.../76-report-of-presidential-taskforce-on-parastatal-reforms.

Sababu, B. M. (2007). Strategic management. The analytical approach. The JKF, Nairobi.

Schein, E. H. (1985). Organizational culture and leadership. San Francisco, CA, Jossey-Bass. https://doi.org/10.1177/027046769401400247.

Scott, W. R. (2004). Institutional Theory: Contributing to a Theoretical Research Program, Stanford University Press. https://doi.org/10.4236/ojbm.2016.42036.

Simon, H. A. (1959). Theories of decision-making in economics and behavioural science. The American Economic Review, 49(3), 253-283.

Venkatraman, N., \& Ramanujam, V. (1986). Measuring business performance in strategy research: a comparison of approaches. The Academy of Management Review, 11(4), 801-814. https://doi.org/10.5465/AMR.1986.4283976.

Wolf, J. \& Engelhoff, W.G. (2002). A re-examination and extension of international strategy-structure theory. Strategic Management Journal, 23, 181-189. https://doi.org/10.1002/smj.210.

World Bank. (2014). Corporate governance of state-owned enterprises: a toolkit. Washington, DC, World Bank. https://doi.org/10.1596/978-1-4648-0222-5.

Zucker, L. (1987). Institutional theories of organizations. Annual Review of Sociology, 13, 443-464. https://doi.org/10.1146/annurev.so.13.080187.002303.

\section{Copyrights}

Copyright for this article is retained by the author(s), with first publication rights granted to the journal.

This is an open-access article distributed under the terms and conditions of the Creative Commons Attribution license (http://creativecommons.org/licenses/by/4.0/). 